\title{
Chrysin, a natural flavonoid enhances steroidogenesis and steroidogenic acute regulatory protein gene expression in mouse Leydig cells
}

\author{
Kuladip Jana ${ }^{1}$, Xiangling Yin ${ }^{2}$, Randolph B Schiffer ${ }^{2}$, Jau-Jiin Chen ${ }^{4}$, Akhilesh K Pandey ${ }^{1}$, Douglas \\ M Stocco ${ }^{3}$, Paula Grammas ${ }^{1}$ and XingJia Wang ${ }^{1}$ \\ ${ }^{1}$ Garrison Institute on Aging, ${ }^{2}$ Department of Neuropsychiatry and ${ }^{3}$ Department of Cell Biology and Biochemistry, Texas Tech University Health Sciences Center, \\ Lubbock, Texas 79430, USA \\ ${ }^{4}$ Department of Nutrition Sciences, University of Nevada, Las Vegas, Nevada 89154, USA \\ (Correspondence should be addressed to X Wang; Email: xingjia.wang@ttuhsc.edu)
}

\begin{abstract}
During the aging process of males, testosterone biosynthesis declines in testicular Leydig cells resulting in decreases in various physiological functions. To explore the possibility of delaying the decline using food supplements, we have studied steroidogenic effects of a natural flavonoid, chrysin, in mouse Leydig cells. Chrysin dramatically increased cyclic AMP (cAMP)-induced steroidogenesis in MA-10 mouse Leydig tumor cells. This result was confirmed using Leydig cells isolated from mouse testes. The steroidogenic effect of chrysin is not associated with an increase in expression of the P450 side-chain cleavage enzyme, required for the conversion of cholesterol to pregnenolone. In addition, when 22(R)hydroxylcholesterol was used as a substrate, chrysin induced a non-significant increase in steroid hormone, suggesting that the majority of the observed increase in steroidogenesis was due to the increased supply
\end{abstract}

of substrate cholesterol. These observations were corroborated by showing that chrysin induced a marked increase in the expression of steroidogenic acute regulatory (StAR) protein, the factor that controls mitochondrial cholesterol transfer. Also, chrysin significantly increased StAR promoter activity and StAR mRNA level. Further studies indicated that this compound depressed expression of DAX-1, a repressor in StAR gene transcription. In the absence of cAMP, chrysin did not increase steroidogenesis. However, when a sub-threshold level of cAMP was used, StAR protein and steroid hormone were increased by chrysin to the levels seen with maximal stimulation of cAMP. These results suggest that while chrysin itself is unable to induce StAR gene expression and steroidogenesis, it appears to function by increasing the sensitivity of Leydig cells to cAMP stimulation.

Journal of Endocrinology (2008) 197, 315-323

\section{Introduction}

It is well documented that blood testosterone concentration declines progressively during the course of male aging, a phenomenon that is associated with decreased bone density, muscle mass and strength, sexual function, and other physiological functions (Vermeulen 2000, Hogervorst et al. 2001, Matsumoto 2002, Kaufman \& Vermeulen 2005). Several longitudinal studies on age-related changes in blood testosterone indicated that the incidence of hypogonadism in males increased with age (Harman et al. 2001, Feldman et al. 2002). Therefore, delaying the decline in blood testosterone is clinically significant for improving the health of aging males.

Testosterone is principally synthesized in testicular Leydig cells under the regulation of luteinizing hormone (LH) and then released into blood (Miller 1988). In the first step of testosterone biosynthesis, the substrate cholesterol is metabolized by the steroidogenic enzyme, P450 side-chain cleavage enzyme (P450scc), and converted to pregnenolone that is further converted to testosterone through the action of several steroidogenic enzymes (Payne \& Youngblood 1995, Payne \& Hales 2004). To initiate steroidogenesis, cholesterol must be transferred from the outer to inner membrane of mitochondria, since the P450scc enzyme is located on the matrix side of the inner mitochondrial membrane and the cholesterol content of the inner membrane is limited (Churchill \& Kimura 1979, Privalle et al. 1983). However, the aqueous space between the outer and inner mitochondrial membranes acts as a barrier to cholesterol transfer because of its hydrophobic nature. As a result, diffusion of cholesterol through this water barrier is very slow and is not able to supply sufficient substrate for adequate testosterone production (Schumacher et al. 1985, Phillips et al. 1987). Therefore, the mitochondrial cholesterol transfer becomes the rate-limiting step in testosterone biosynthesis. We have 
previously reported that the steroidogenic acute regulatory (StAR) protein plays a critical function at this step by facilitating the cholesterol transfer (Clark et al. 1994, Lin et al. 1995, Wang et al. 1998). It was well demonstrated that LH stimulation of Leydig cells induces StAR gene expression, and the level of StAR protein in Leydig cells significantly affects testosterone production (Stocco 2001). However, StAR protein level also declines during Leydig cell aging, and mitochondrial cholesterol transfer in aged rat Leydig cells is defective (Leers-Sucheta et al. 1999, Luo et al. 2001, Culty et al. 2002). These studies indicated that the age-related decrease in StAR gene expression is involved in the decrease in testosterone biosynthesis in aging Leydig cells. Our previous studies suggested that it is possible to delay the decline in testosterone biosynthesis by increasing the StAR gene expression (Wang et al. 2003a, 2005). Based on the observations in these studies, we were able to reverse the agerelated declines in StAR protein expression and blood testosterone concentration by feeding the aging rats with a drug to inhibit the activity of cyclooxygenase-2 (COX2), an enzyme whose activity is inhibitory to StAR gene expression (Wang et al. 2005). However, aging is a long process and the long-term application of pharmacological levels of COX2 inhibitors is limited by their potential side effects on health. Therefore, we have attempted to identify natural compounds in food and food supplements that have fewer side effects and effectively increase StAR gene expression and testosterone biosynthesis in Leydig cells. A natural flavonoid, chrysin, was previously used to increase blood testosterone (Brown et al. 2001a,b, Dhawan et al. 2002). We have studied the steroidogenic effect of this flavonoid and found that chrysin significantly enhanced steroidogenesis in Leydig cells mainly by increasing the StAR gene expression.

\section{Materials and Methods}

\section{Reagents}

$N^{6}$,2-dibutyryladenosine 3:5-cyclic monophosphate (dbcAMP), chrysin, H89, nordihydroguaiaretic acid (NDGA), AA861 and Waymouth's MB/752 medium were purchased from Sigma. Rabbit antiserum generated against StAR protein was a generous gift from Dr W L Miller (Bose et al. 1999). The monoclonal antibody against DAX-1 (dosage-sensitive sex reversal-adrenal hypoplasia congenita critical region on the $\mathrm{X}$ chromosome gene 1) protein was a generous gift from Dr P Sassone-Corsi (Université Louis Pasteur, Strasbourg, France). Donkey anti-rabbit IgG antibody conjugated with horseradish peroxidase was purchased from Biosource (Camarillo, CA, USA). Horse serum was purchased from Invitrogen. The Dual-Luciferase Reporter Assay System was purchased from Promega. Other common chemicals used in this study were obtained from either Sigma or Fisher Chemicals (Pittsburgh, PA, USA).

\section{MA-10 cell culture}

The MA-10 mouse Leydig tumor cell line was a generous gift from Dr Mario Ascoli (Department of Pharmacology, University of Iowa, College of Medicine, Iowa City, IA, USA). The cells were cultured in six-well culture plates in Waymouth's MB/752 medium containing 15\% horse serum as described previously (Ascoli 1981) in an incubator at $37^{\circ} \mathrm{C}$ with $5 \% \mathrm{CO}_{2}$. Before each experiment, the medium was replaced with serum-free Waymouth's medium.

\section{Steroid hormone production}

MA-10 cells were cultured for $30 \mathrm{~min}$ in serum-free Waymouth's medium in six-well plates with or without chrysin (as described in the Figure Legends) and then $0.05 \mathrm{mM}$ dbcAMP was added to the culture for $6 \mathrm{~h}$. The medium was collected at the end of each experiment and stored at $-80^{\circ} \mathrm{C}$. Progesterone concentrations in the medium were determined by RIA (Resko et al. 1974).

\section{Mouse Leydig cell isolation and cell culture}

B6-129S7 mice aged 3 months (Jackson Laboratory, Bar Harbor, ME, USA) were euthanized in a chamber filled with carbon dioxide followed by cervical dislocation. Testes were collected from the mice. Leydig cells were isolated from the testes using density gradient centrifugation as described previously (Hutson et al. 1996). The cells were cultured in 12-well plates with DMEM/F-12 medium containing 0 $1 \%$ BSA at $32{ }^{\circ} \mathrm{C}$ and $5 \% \mathrm{CO}_{2}$. After $2 \mathrm{~h}$ of culture, the cells were incubated with chrysin for $30 \mathrm{~min}$ in DMEM/F-12 medium without BSA and then $0.05 \mathrm{mM}$ dbcAMP was added to the culture for $4 \mathrm{~h}$. The culture medium and Leydig cells were collected and stored at $-80^{\circ} \mathrm{C}$. Testosterone concentrations in the medium were determined by RIA. All procedures were approved by the Texas Tech University Health Sciences Center Animal Care and Use Committee.

\section{Western blot analysis}

StAR protein, P450scc, and DAX-1 protein in Leydig cells were detected by western blot analysis as described previously (Townson et al. 1996). Western blot analysis experiments were performed at least three times and the results of one representative experiment are shown for each figure.

\section{Transfection}

MA-10 cells were cultured in 12 -well plates $\left(0 \cdot 2 \times 10^{6}\right.$ cells per well) overnight. The cells in each well were transfected with $0.5 \mu \mathrm{g}$ DNA of the StAR promoter/luciferase plasmid PGL2/StAR expressing firefly luciferase driven by the - 966 bp sequence of the StAR promoter (Caron et al. 1997). Transfections also included $6 \cdot 0 \mathrm{ng}$ of the pRL-SV40 vector DNA (a plasmid that constitutively expresses Renilla luciferase 
under the control of the SV40 promoter, Promega). Transfections were performed using FuGENE6 Transfection Reagent (Roche) following the manufacturer's instructions. After $48 \mathrm{~h}$ of culture, the cells were utilized for further experiments.

\section{Luciferase assays}

Following experiments, the cells were washed three times with ice-cold PBS and lysed with Passive Lysis Buffer (Promega). The supernatants were utilized for luciferase assays using a Dual Luciferase Reporter Assay System following the manufacturer's instructions (Promega). The Relative Light Units (determined by dividing the reading from the PGL2/StAR promoter by the reading from Renilla luciferase) were measured using a TD-20/20 luminometer (Turner Designers, Sunnyvale, CA, USA).

\section{RT-PCR}

In experiments designed to determine StAR or DAX-1 mRNA expression, cells were washed three times with cold PBS and used for total RNA purification using TRIzol reagent in accordance with the manufacturer's instructions (Invitrogen). The first-strand cDNA was synthesized from total RNA using the Reverse Transcription System (Promega). PCR for StAR was performed as previously described (Rao et al. 2003). PCR for DAX-1 was performed with the forward primer $5^{\prime}$-TCCTGTACCGCAGCTATGTG- $3^{\prime}$ and the reverse primer $5^{\prime}$-TCGAAGTGCAGGTGATCTTG- $3^{\prime}$, for 32 cycles at $94^{\circ} \mathrm{C}$ for $1.5 \mathrm{~min}$, $55^{\circ} \mathrm{C}$ for $1.5 \mathrm{~min}, 72{ }^{\circ} \mathrm{C}$ for $2.5 \mathrm{~min}$, and then followed by incubation at $72{ }^{\circ} \mathrm{C}$ for $15 \mathrm{~min}$. $\beta$-Actin was used as an internal marker in PCR for DAX-1.

\section{Protein kinase $A$ activity assays}

Protein kinase A (PKA) activity was assayed as described previously (Wang et al. 2003a), using the SignaTecT cAMPdependent protein kinase assay system (Promega) following the manufacturer's instruction. PKA activity was expressed as picomoles of ${ }^{32} \mathrm{P}$ incorporated per min per $\mu \mathrm{g}$ protein.

\section{Statistical analysis}

Each experiment was repeated at least three times. Statistical analysis of the data was performed with ANOVA using the GraphPad Prism 4 system (GraphPad Software, San Diego, CA, USA). The data are shown as the mean \pm s.E.M.

\section{Results}

\section{Chrysin-enhanced steroid hormone production}

To study the effect of chrysin on Leydig cell steroidogenesis, MA-10 mouse Leydig cells were incubated with increasing concentrations of chrysin and $0 \cdot 05 \mathrm{mM}$ dbcAMP. Incubation of MA-10 cells with chrysin induced a concentration-dependent increase in steroid hormone production. When the chrysin concentrations in the culture were increased from 0 to $10 \mu \mathrm{M}$, progesterone production was increased from $8 \cdot 4$ to $42 \cdot 2 \mathrm{ng} / \mathrm{ml}$ (Fig. 1). To verify the results, the Leydig cells isolated from mice were cultured in the medium containing $10 \mu \mathrm{M}$ chrysin and 0.05 mM dbcAMP. Incubation of the mouse Leydig cells with chrysin significantly enhanced steroidogenesis, with testosterone production being increased $2 \cdot 4$-fold over that of the cells stimulated with 0.05 mM dbcAMP alone (Fig. 2).

$\mathrm{P} 450 \mathrm{scc}$ expression was analyzed by western blot analysis to determine whether the increase in steroid hormone is due to an increase in P450scc expression. As shown in the Fig. 3, chrysin did not affect P450scc expression. Further, the hydrophilic substrate, 22(R)hydroxylcholesterol, was used to examine the effects of chrysin on the activities of steroidogenic enzymes. It was shown that chrysin induced a slight, but non-significant increase in progesterone production (Fig. 3).

\section{Chrysin-enhanced StAR protein expression}

Western blot analysis was performed to determine whether StAR protein levels in the chrysin-treated Leydig cells were altered. Incubation of MA-10 cells with the increasing concentrations of chrysin resulted in an increase in StAR protein expression in a concentration-dependent manner, paralleling the increase in steroid hormone production (Fig. 1). Also, incubation of the mouse Leydig cells with $10 \mu \mathrm{M}$ chrysin enhanced cAMP-induced StAR protein expression concomitantly with the increase in testosterone production (Fig. 2).

\section{A StAR protein}

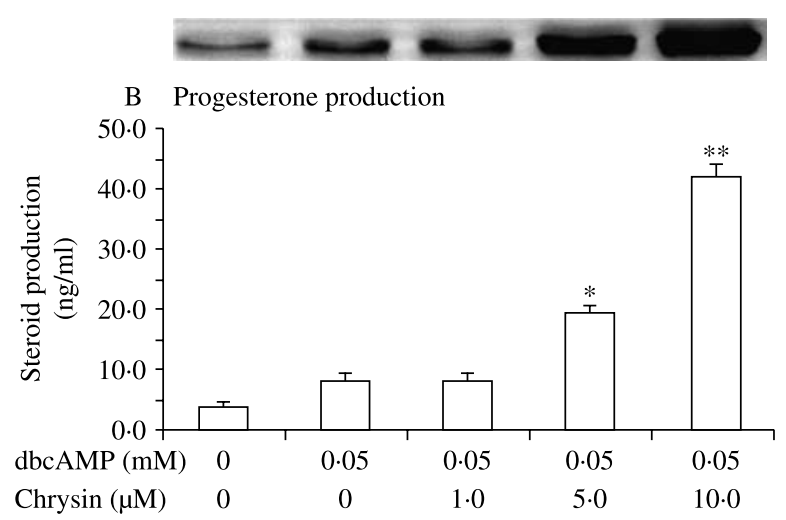

Figure 1 Concentration-dependent increases in StAR protein expression and steroidogenesis in MA-10 mouse Leydig cells treated with chrysin. MA-10 cells were cultured with increasing concentrations of chrysin for $30 \mathrm{~min}$ and then $0.05 \mathrm{mM}$ dbcAMP was added to the culture for $6 \mathrm{~h}$. (A) The cells were collected and $20 \mu \mathrm{g}$ cell lysate protein was used for western blot analysis of StAR protein. (B) The culture medium was collected and progesterone production was assessed by RIA. ${ }^{*} P<0 \cdot 05,{ }^{* *} P<0 \cdot 01$ compared with the cells treated with $0.05 \mathrm{mM}$ dbcAMP alone. 
A StAR protein

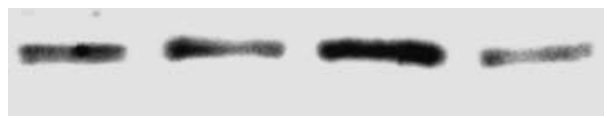

B Testosterone production

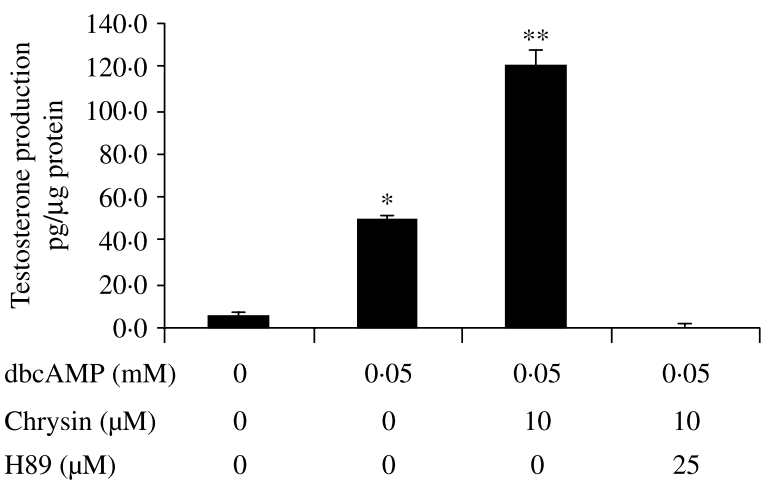

Figure 2 Chrysin-enhanced StAR protein expression and testosterone production in the Leydig cells isolated from mouse testes. The Leydig cells were isolated from the testes of 3 month-old mice. The cells were incubated with chrysin and $\mathrm{H} 89$ for $30 \mathrm{~min}$ and then $0.05 \mathrm{mM} \mathrm{dbcAMP}$ was added to the culture for $4 \mathrm{~h}$. (A) The cells were collected and $5 \mu \mathrm{g}$ cell lysate protein was used for western blot analysis of StAR protein. (B) The culture medium was collected and testosterone production was assessed by RIA. ${ }^{*} P<0 \cdot 05,{ }^{* *} P<0 \cdot 01$ compared with control.

\section{Chrysin-enhanced StAR gene transcription}

Luciferase assay of StAR promoter activity and RT-PCR analysis of StAR mRNA levels were performed to determine the effect of chrysin on StAR gene transcription. Similar to its effects on StAR protein expression and

\section{A P450scc}
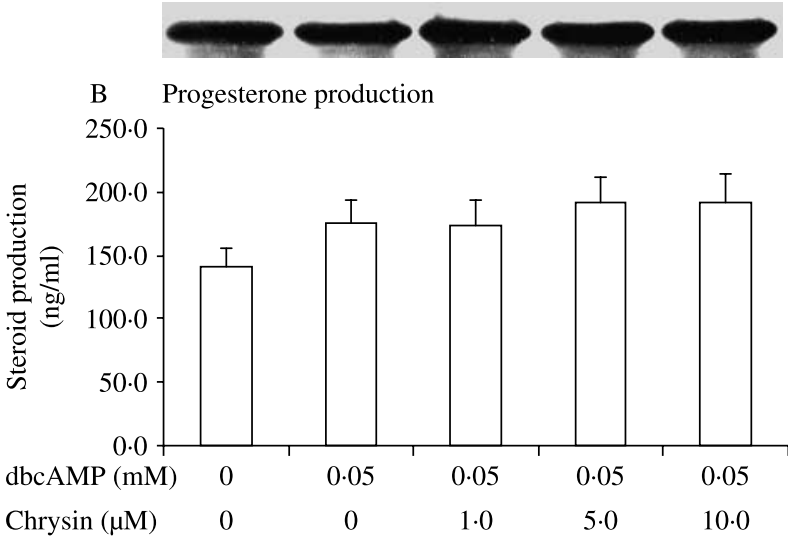

Figure 3 P450scc expression and steroid hormone production in MA-10 mouse Leydig cells using 22(R)hydroxylcholesterol as a substrate. MA-10 cells were cultured with $25 \mu \mathrm{M} 22(\mathrm{R})$ hydroxylcholesterol. The cells were incubated with increasing concentrations of chrysin for $30 \mathrm{~min}$ and then $0.05 \mathrm{mM}$ dbcAMP was added to the culture for $6 \mathrm{~h}$. (A) The cells were collected and $20 \mu \mathrm{g}$ cell lysate protein was used for western blot analysis of P450scc protein. (B) The culture medium was collected and progesterone production was assessed by RIA. There is no significant difference in steroid production among the groups $(P>0 \cdot 05)$. steroidogenesis, the increasing levels of chrysin significantly increased cAMP-induced StAR promoter activity and StAR mRNA levels in a concentration-dependent manner. In MA-10 cell cultures, $10 \mu \mathrm{M}$ chrysin induced a 12-fold increase in StAR promoter activity (Fig. 4).

\section{Synergistic interaction between chrysin and cAMP in steroidogenesis}

MA-10 cells were incubated with increasing concentrations of dbcAMP in the medium containing $10 \mu \mathrm{M}$ chrysin to study the interaction between chrysin and cAMP. The results indicated that chrysin did not increase StAR protein expression and steroid hormone production in the absence of dbcAMP. However, in the presence of sub-threshold level of dbcAMP $(0.05 \mathrm{mM})$, chrysin dramatically increased StAR protein expression and steroidogenesis (Fig. 5). Similarly, 0.05 or $0.1 \mathrm{mM}$ dbcAMP alone is unable to induce significant increases in StAR protein and steroid hormone. However, in the presence of $10 \mu \mathrm{M}$ chrysin, low level of cAMP is able to induce maximal levels of StAR protein expression and steroidogenesis, with $0.1 \mathrm{mM}$ dbcAMP increasing progesterone production to tenfold over that seen in the paired group treated with dbcAMP alone.

\section{A RT-PCR analysis of StAR mRNA}
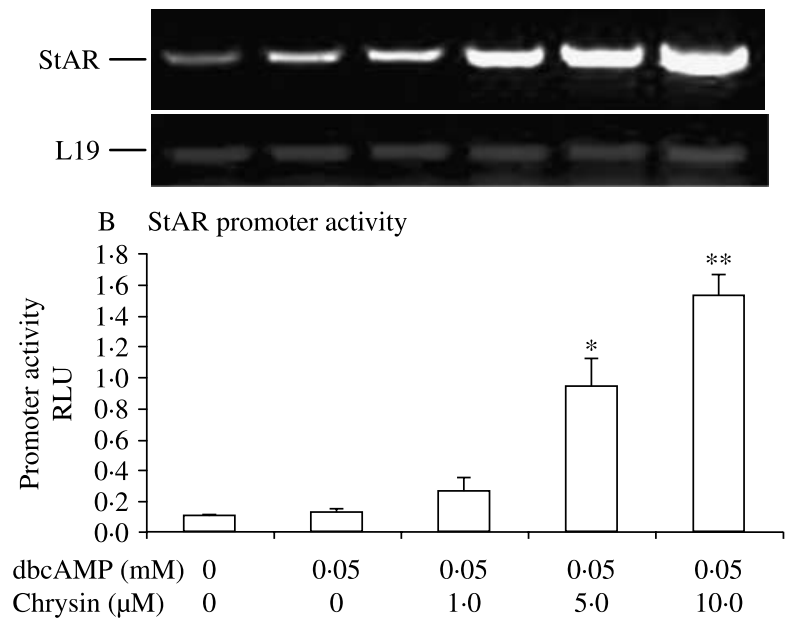

Figure 4 Concentration-dependent increase in StAR gene transcription in MA-10 mouse Leydig cells treated with chrysin. MA-10 cells were cultured with increasing concentrations of chrysin for $30 \mathrm{~min}$ and then $0.05 \mathrm{mM} \mathrm{dbcAMP}$ was added to the culture for $6 \mathrm{~h}$. (A) The cells were collected for total RNA isolation and StAR mRNA was analyzed by RT-PCR using the rRNA L19 as an internal marker. (B) MA-10 cells were transfected with a StAR promoter/luciferase plasmid (PGL2/StAR) and a pRLSV40 vector, a plasmid that constitutively expresses Renilla luciferase. The cell lysate was used for luciferase assays using a Dual Luciferase Reporter Assay System. ${ }^{*} P<0 \cdot 05,{ }^{* *} P<0 \cdot 01$ compared with the cells treated with $0.05 \mathrm{mM}$ dbcAMP alone. 
A StAR protein

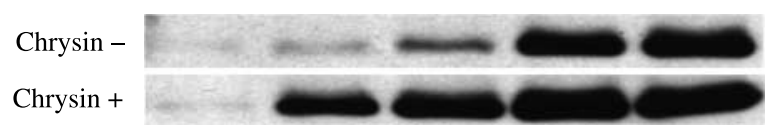

B

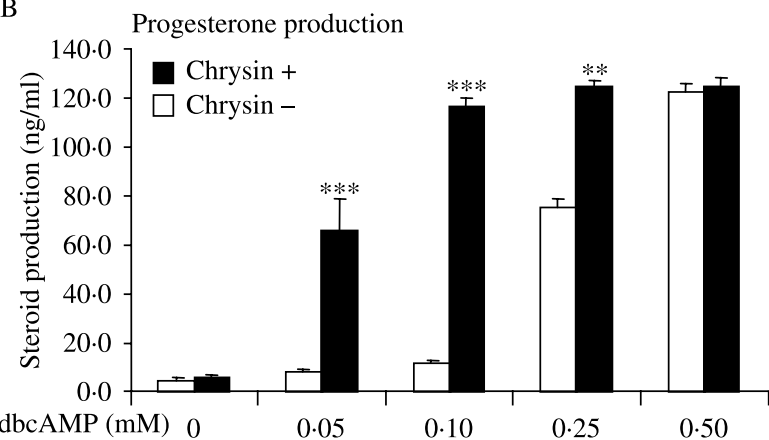

Figure 5 Chrysin-increased steroidogenic sensitivity of MA-10 mouse Leydig cells to cAMP stimulation. MA-10 cells were cultured for $30 \mathrm{~min}$ with or without $10 \mu \mathrm{M}$ chrysin and then the increasing concentrations of dbcAMP were added to the cultures for $6 \mathrm{~h}$. (A) The cells were collected and $20 \mu \mathrm{g}$ cell lysate protein was used for western blot analysis of StAR protein. (B) The culture medium was collected and progesterone production was assessed by RIA. ${ }^{* *} P<0 \cdot 01, * * * P<0 \cdot 001$ compared with the paired groups treated with dbcAMP alone.

\section{DAX-1 expression in chrysin-treated cells}

To further understand how chrysin enhanced StAR gene transcription, DAX-1 protein was detected by western blot. The results shown in Fig. 6 indicated that expression of DAX-1 protein was maintained at a high level in MA-10 cells. While stimulation of the cells with $0.05 \mathrm{mM}$ dbcAMP did not reduce DAX-1 protein, co-incubation with $10 \mu \mathrm{M}$ chrysin markedly reduced DAX-1 protein in MA-10 cells. When DAX-1 protein was reduced, StAR protein and steroidogenesis were significantly increased. Similar results were obtained in RT-PCR analysis of DAX-1 mRNA. The results in Fig. 7 indicated that while chrysin alone only slightly reduced DAX-1 expression, the co-action of chrysin and $0.05 \mathrm{mM}$ dbcAMP dramatically reduced DXA-1 protein and mRNA levels.

\section{The essential role of PKA activity in chrysin-enhanced steroidogenesis}

PKA activity in chrysin-treated Leydig cells was inhibited using an inhibitor H89 to determine the role of PKA activity in the increased StAR protein expression. As shown in Fig. 6, while $10 \mu \mathrm{M}$ chrysin dramatically enhanced cAMP-induced StAR protein and steroid hormone production, the inhibition of PKA activity resulted in a marked reduction in StAR protein expression. Progesterone production by MA-10 cells was reduced to $5 \%$ by the PKA inhibitor. Testosterone production by the isolated Leydig cells was also reduced to $2 \cdot 5 \%$ (Fig. 2 ).

\section{A DAX-1 protein}

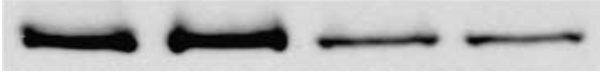

B StAR protein

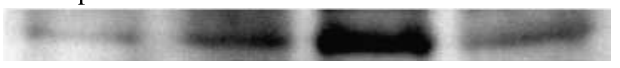

C Progesterone production

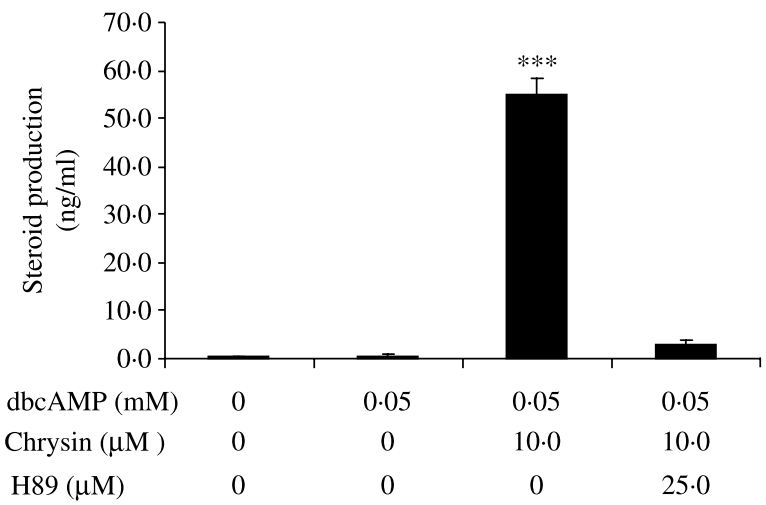

Figure 6 Reduction in DAX-1 protein and increase in steroidogenesis in chrysin-treated MA-10 mouse Leydig cells. MA-10 cells were cultured for $30 \mathrm{~min}$ in serum-free Waymouth's medium containing chrysin and $\mathrm{H} 89$. Then $0.05 \mathrm{mM}$ dbcAMP was added to the culture for $6 \mathrm{~h}$. (A) The cells were collected and $20 \mu \mathrm{g}$ cell lysate protein was used for western blot analyses of DAX-1 protein and StAR protein. (B) The culture medium was collected and progesterone production was assessed by RIA. ${ }^{* * *} P<0 \cdot 001$ compared with the cells treated with $0.05 \mathrm{mM}$ dbcAMP alone.

To verify the role of PKA in the observed results, PKA activities in MA-10 cells were assayed. Results from the assays indicated that while PKA activity in the cells was significantly increased by $0.05 \mathrm{mM}$ dbcAMP, it was not affected by $10 \mu \mathrm{M}$ chrysin. When $25 \mu \mathrm{M}$ H89 was added to the culture, dbcAMP-increased PKA activity was significantly reduced (Fig. 7).

The essential role of lipoxygenase activity in chrysin-enhanced steroidogenesis

The above results and previous studies (Wang et al. 2000, 2002) encouraged us to determine the role of arachidonic acid (AA)-mediated signaling in chrysin-induced steroidogenesis. MA-10 cells were cultured for $30 \mathrm{~min}$ with chrysin in a medium containing lipoxygenase inhibitor, NDGA, or 5-lipoxygenase inhibitor, AA861. Then $0.05 \mathrm{mM}$ dbcAMP was added to the culture for $6 \mathrm{~h}$ as indicated in Fig. 8. Similar to the above observations, $10 \mu \mathrm{M}$ chrysin significantly enhanced steroidogenesis. However, the results from RIA and western blot analysis indicated that the chrysin-increased StAR protein and steroid hormone production were dramatically reduced when the lipoxygenase activities in the cells were inhibited (Fig. 8). 
A RT-PCR analysis of DAX-1 mRNA

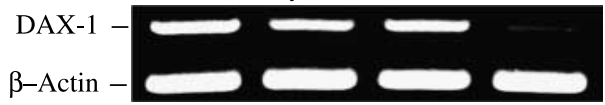

B DAX-1 protein
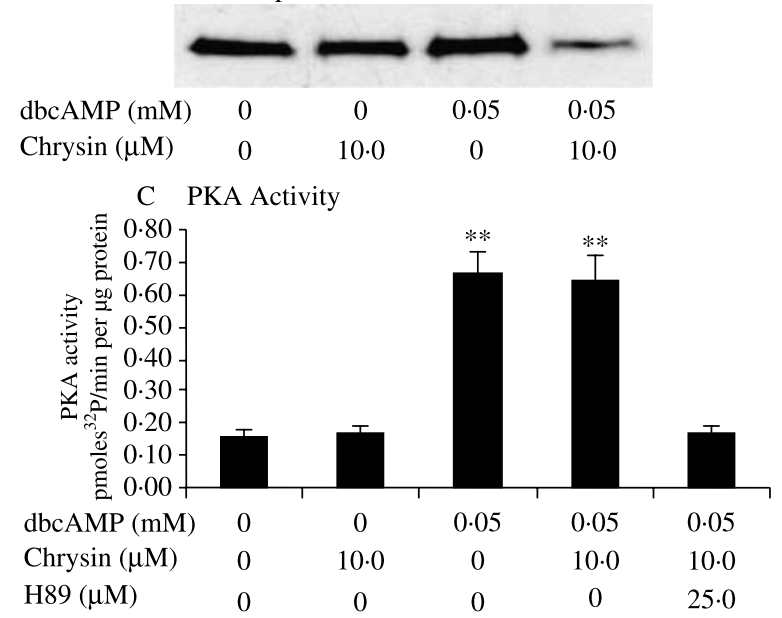

Figure 7 Effects of chrysin on PKA activities and DXA-1 mRNA levels in MA-10 mouse Leydig cells. MA-10 cells were cultured for 30 min with or without $\mathrm{H} 89$ in a medium containing $10 \mu \mathrm{M}$ chrysin. Then $0.05 \mathrm{mM}$ dbcAMP was added to the culture for $6 \mathrm{~h}$ as indicated in the figure. (A) The cells were collected for total RNA isolation and DAX-1 mRNA was analyzed by RT-PCR using the $\beta$-actin as an internal marker. (B) The cells were collected and $20 \mu \mathrm{g}$ cell lysate protein was used for western blot analyses of DAX-1 protein. (C) Cell extract was used for PKA activity assays. ${ }^{* *} P<0 \cdot 01$ compared with the cells treated with $\mathrm{H} 89$.

\section{Discussion}

Chrysin is one of the natural flavonoids present in plants (Rapta et al. 1995, Williams et al. 1997). It is present in honey and propolis at high levels (Gambelunghe et al. 2003). In addition to its activities in anti-cancer (Cardenas et al. 2006), anti-oxidation (Lapidot et al. 2002), and antiinflammation (Cho et al. 2004), chrysin has also been reported to be an inhibitor of aromatase (Kellis \& Vickery 1984, Ibrahim \& Abul-Hajj 1990), an enzyme that converts testosterone to estrogen. Based on these studies, chrysin has been considered to be a testosterone-increasing agent by blocking the further metabolism of testosterone by aromatase (Dhawan et al. 2002). We have been interested in its testosterone-increasing activity and examined it with MA10 mouse Leydig cells and Leydig cells isolated from mouse testes. The results of the present study suggest that chrysin increases testosterone biosynthesis mainly by enhancing cAMP-induced StAR gene expression in Leydig cells.

The steroidogenic effect of chrysin was indicated by the concentration-dependent increase in steroid hormone production in MA-10 mouse Leydig cells incubated with increasing concentrations of chrysin in culture medium containing $0.05 \mathrm{mM}$ dbcAMP. This effect was confirmed in primary cultures utilizing Leydig cells isolated from mouse

\section{A StAR protein}

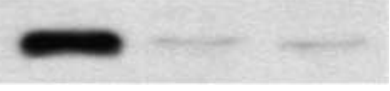

B Progesterone production

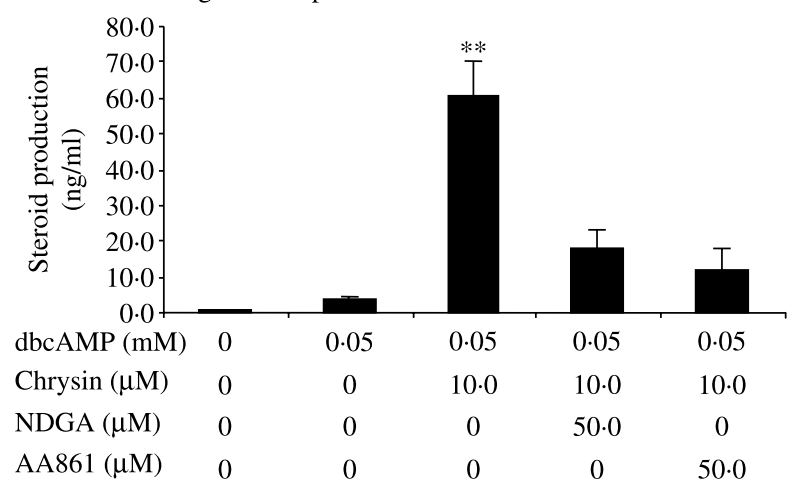

Figure 8 Reductions in StAR protein expression and steroid hormone production in MA-10 mouse Leydig cells treated with lipoxygenase inhibitors. MA-10 cells were cultured for $30 \mathrm{~min}$ with chrysin in a medium containing lipoxygenase inhibitor, NDGA, or 5-lipoxygenase inhibitor, AA861. Then $0.05 \mathrm{mM}$ dbcAMP was added to the culture for $6 \mathrm{~h}$ as indicated in the figure. (A) The cells were collected and $20 \mu$ g cell lysate protein was used for western blot analyses of StAR protein. (B) The culture medium was collected and progesterone production was assessed by RIA. ${ }^{* *} P<0 \cdot 01$ compared with the cells treated with NDGA.

testes, with testosterone production being dramatically enhanced when the cells were treated with chrysin. While chrysin enhanced dbcAMP-stimulated steroidogenesis, it did not affect P450scc expression. Also, when water-soluble 22(R)hydroxylcholesterol was used as the substrate, steroid hormone production in each group reached the maximal level, and there is no significant difference in steroidogenesis among the groups. In these groups, chrysin only induced a slight, non-significant increase in steroid hormone production. These observations indicated that the majority of the increase in steroid hormone did not result from increases in the activities of steroidogenic enzymes, but rather, from the increased supply of the substrate cholesterol to the inner mitochondrial membrane. These observations were corroborated by the results from western blot analysis of StAR protein in MA-10 Leydig cells and also in primary cultures of Leydig cells isolated from mouse testes. In these cells, chrysin induced a marked increase in StAR protein, the factor that facilitates mitochondrial cholesterol transfer to the P450scc enzyme. Also, the increase in StAR protein occurred concomitantly with the increase in steroid hormone production. Moreover, reduction in StAR protein expression by inhibiting PKA activity abolished the chrysin-enhanced steroidogenesis in Leydig cells.

Normally, low levels of dbcAMP, such as $0.05 \mathrm{mM}$, are unable to induce significant increases in StAR protein and steroidogenesis in MA-10 Leydig cells. However, in the presence of chrysin, $0.05 \mathrm{mM}$ of dbcAMP significantly 
increased StAR protein and steroid hormone production. The effectiveness of dbcAMP stimulation was dramatically enhanced in the chrysin-treated cells, with StAR protein expression and steroidogenesis reaching their maximal levels at much lower concentrations of dbcAMP than those in the cells without chrysin. On the other hand, although chrysin strongly enhanced cAMP-stimulated steroidogenesis, in the absence of cAMP chrysin did not induce a significant increase in StAR protein or steroid hormone. Also, inhibition of PKA activity reduced chrysin-induced StAR protein and steroidogenesis. These results suggested that this flavonoid is unable to stimulate StAR protein expression by itself, but rather interacted with cAMP and reduced the threshold of cAMPstimulated StAR protein expression, resulting in increase in the sensitivity of Leydig cells to cAMP stimulation.

How chrysin interacted with cAMP to increase sensitivity of Leydig cells to cAMP stimulation is unknown. It was demonstrated that in cAMP-stimulated steroidogenesis, both cAMP-PKA phosphorylation and AA-mediated signaling pathways are required for StAR gene expression (Wang et al. 2000). These two signaling pathways synergistically interact with each other, with an increase of signal in either pathway dramatically enhancing sensitivity of Leydig cells to cAMP stimulation (Wang et al. 2002, 2003b). Based on these studies, we have examined the roles of these two signaling pathways in chrysin-enhanced steroidogenesis. The results from PKA activity assays indicated that while PKA activity is critical for the observed increase in StAR protein expression, chrysin did not enhance the cAMP-PKA phosphorylation signaling. However, when AA metabolism by 5-lipoxygenase was blocked, the increases in StAR protein and steroid hormone in the chrysin-treated cells were reversed, suggesting that AA-mediated signaling is involved in the chrysin-increased StAR protein expression. Since 5-lipoxygenase-generated AA metabolites significantly enhanced steroidogenic sensitivity of Leydig cells to cAMP stimulation (Wang et al. 2003b), it is interesting to determine if chrysin enhances this AA-mediated signaling.

While the manner in which chrysin interacted with cAMP is awaiting further elucidation, the evidence from the present study indicates that this interaction enhanced StAR gene expression at the level of transcription. This could be readily seen from the luciferase assays of StAR promoter activity, which indicated that incubation of cAMP-treated MA-10 cells with chrysin induced a concentration-dependent increase in StAR promoter activity. Similar results were obtained in RT-PCR analysis of StAR mRNA levels. To further understand how this natural flavonoid enhanced StAR gene transcription, the transcription factors regulating StAR promoter activity were examined. It was found that when MA-10 Leydig cells were incubated with chrysin in a medium containing $0.05 \mathrm{mM}$ dbcAMP, DAX-1 protein and DAX-1 mRNA levels in the cells were markedly reduced. DAX-1 protein is a powerful transcriptional repressor that binds to a hairpin structure in StAR promoter DNA and inhibits StAR gene transcription (Zazopoulos et al. 1997). The results suggest that interaction between chrysin and cAMP enhance
StAR gene transcription by depressing DAX-1 gene expression. The results in Figs 6 and 7 further indicated that DAX-1 is constitutively expressed in MA-10 Leydig cells, generating a tonic inhibition of StAR gene transcription (Zazopoulos et al. 1997). Thus, the reduction of DAX-1generated tonic inhibition resulted in the increase in sensitivity of Leydig cells to cAMP stimulation.

In addition to the transcriptional regulation, StAR gene expression is also regulated at the level of post-transcription. Regarding this, the studies in the recent years have described a cAMP-regulated turnover and stability of StAR mRNA (Zhao et al. 2005), in which cAMP selectively induced an unstable form of StAR mRNA to facilitate rapid increase and decrease in StAR expression. Also, the effect of cAMP on the post-transcriptional regulation of StAR expression involves A-kinase anchoring proteins (AKAPs). AKAPs recruit StAR mRNA and PKA to the mitochondria and facilitate StAR translation and phosphorylation (Dyson et al. 2008, Papadopoulos et al. 2007). However, whether chrysin enhanced the cAMP-regulated post-transcriptional regulation of StAR gene expression needs to be clarified by experimental evidence.

Taken together, the present study suggests a potential for the application of chrysin to delay the age-related decline in StAR gene expression and testosterone biosynthesis in Leydig cells. This is supported by studies using aged male rats, in which supplementation with chrysin for 30 days significantly improved the reproductive functions of the animals (Dhawan et al. 2002). The effectiveness of chrysin might be attenuated by its low bioavailability in some food supplements (Gambelunghe et al. 2003). Recent studies have attempted to improve the effectiveness of chrysin by modification of its molecular structure (Dao et al. 2004). Several chrysin derivatives with improved activities were reported. Interestingly, some of these derivatives are able to bind to the COX2 molecule and selectively inhibits COX2 activity (Cho et al. 2004). We have previously reported that inhibition of COX2 activity dramatically enhanced StAR gene expression and steroidogenesis in aging Leydig cells (Wang et al. 2005). Thus, these derivatives with COX2-inhibiting activity may significantly improve the steroid synthesis-promoting activity of chrysin.

Obviously, more studies, especially long-term clinical studies, are needed to test the efficacy of chrysin or its derivatives on delaying the age-related decline in blood testosterone. Since the decline in testosterone is associated with decreases in various physiological functions, further studies on the steroidogenic effect of chrysin may be beneficial for aging males, especially for those suffering from hypogonadism.

\section{Acknowledgements}

The authors would like to acknowledge the support of NIH Grant AG025349 to X J W, NIH Grants AG028367 to P G, 
and NIH grant HD-17481 and funds from the Robert A Welch Foundation grant B1-0028 to D M S. The authors declare that there is no conflict of interest that would prejudice the impartiality of this scientific work.

\section{References}

Ascoli M 1981 Characterization of several clonal lines of cultured Leydig tumor cells: gonadotropin receptors and steroidogenic responses. Endocrinology 108 88-95.

Bose HS, Whittal RM, Baldwin MA \& Miller WL 1999 The active form of the steroidogenic acute regulatory protein, StAR, appears to be a molten globule. PNAS 96 7250-7255.

Brown GA, Vukovich MD, Martini ER, Kohut ML, Franke WD, Jackson DA \& King DS 2001 $a$ Endocrine and lipid responses to chronic androstenediolherbal supplementation in 30 to 58 year old men. Journal of the American College of Nutrition 20 520-528.

Brown GA, Vukovich MD, Martini ER, Kohut ML, Franke WD, Jackson DA \& King DS $2001 b$ Effects of androstenedione-herbal supplementation on serum sex hormone concentrations in 30- to 59-year-old men. International Journal for Vitamin and Nutrition Research 71 293-301.

Cardenas M, Marder M, Blank VC \& Roguin LP 2006 Antitumor activity of some natural flavonoids and synthetic derivatives on various human and murine cancer cell lines. Bioorganic and Medicinal Chemistry 14 2966-2971.

Caron KM, Ikeda Y, Soo SC, Stocco DM, Parker KL \& Clark BJ 1997 Characterization of the promoter region of the mouse gene encoding the steroidogenic acute regulatory protein. Molecular Endocinology 11 138-147.

Cho H, Yun CW, Park WK, Kong JY, Kim KS, Park Y, Lee S \& Kim BK 2004 Modulation of the activity of pro-inflammatory enzymes, COX-2 and iNOS, by chrysin derivatives. Pharmacology Research 49 37-43.

Churchill PF \& Kimura T 1979 Topological studies of cytochromes P-450scc and $\mathrm{P}-45011$ beta in bovine adrenocortical inner mitochondrial membranes. Effects of controlled tryptic digestion. Journal of Biological Chemistry 254 10443-10448.

Clark BJ, Wells J, King SR \& Stocco DM 1994 The purification, cloning, and expression of a novel luteinizing hormone-induced mitochondrial protein in MA-10 mouse Leydig tumor cells. Characterization of the steroidogenic acute regulatory protein (StAR). Journal of Biological Chemistry 269 28314-28322.

Culty M, Luo L, Yao ZX, Chen H, Papadopoulos V \& Zirkin BR 2002 Cholesterol transport, peripheral benzodiazepine receptor, and steroidogenesis in aging Leydig cells. Journal of Andrology 23 439-447.

Dao TT, Chi YS, Kim J, Kim HP, Kim S \& Park H 2004 Synthesis and inhibitory activity against COX-2 catalyzed prostaglandin production of chrysin derivatives. Bioorganic and Medicinal Chemistry Letters 14 1165-1167.

Dhawan K, Kumar S \& Sharma A 2002 Beneficial effects of chrysin and benzoflavone on virility in 2-year-old male rats. Journal of Medicinal Food 5 43-48.

Dyson MT, Jones JK, Kowalewski MP, Manna PR, Alonso M, Gottesman ME \& Stocco DM 2008 Mitochondrial A-kinase anchoring protein 121 binds type II protein kinase A and enhances steroidogenic acute regulatory protein-mediated steroidogenesis in MA-10 mouse Leydig tumor cells. Biology of Reproduction 78 267-277.

Feldman HA, Longcope C, Derby CA, Johannes CB, Araujo AB, Coviello AD, Bremner WJ \& McKinlay JB 2002 Age trends in the level of serum testosterone and other hormones in middle-aged men: longitudinal results from the Massachusetts male aging study. Journal of Clinical Endocrinology and Metabolism 87 589-598.

Gambelunghe C, Rossi R, Sommavilla M, Ferranti C, Rossi R, Ciculi C, Gizzi S, Micheletti A \& Rufini S 2003 Effects of chrysin on urinary testosterone levels in human males. Journal of Medicinal Food 6 387-390.

Harman SM, Metter EJ, Tobin JD, Pearson J \& Blackman MR 2001 Longitudinal effects of aging on serum total and free testosterone levels in healthy men. Baltimore Longitudinal Study of Aging. Journal of Clinical Endocrinology and Metabolism 86 724-731.
Hogervorst E, Williams J, Budge M, Barnetson L, Combrinck M \& Smith AD 2001 Serum total testosterone is lower in men with Alzheimer's disease. Neuro Endocrinology Letters 22 163-168.

Hutson JC, Garner CW \& Doris PA 1996 Purification and characterization of a lipophilic factor from testicular macrophages that stimulates testosterone production by Leydig cells. Journal of Andrology 17 502-508.

Ibrahim AR \& Abul-Hajj YJ 1990 Aromatase inhibition by flavonoids. Journal of Steroid Biochemistry and Molecular Biology 37 257-260.

Kaufman JM \& Vermeulen A 2005 The decline of androgen levels in elderly men and its clinical and therapeutic implications. Endocrine Reviews 26 833-876.

Kellis JT Jr \& Vickery LE 1984 Inhibition of human estrogen synthetase (aromatase) by flavones. Science 225 1032-1034.

Lapidot T, Walker MD \& Kanner J 2002 Antioxidant and prooxidant effects of phenolics on pancreatic beta-cells in vitro. Journal of Agricultural and Food Chemistry 50 7220-7225.

Leers-Sucheta S, Stocco DM \& Azhar S 1999 Down-regulation of steroidogenic acute regulatory (StAR) protein in rat Leydig cells: implications for regulation of testosterone production during aging. Mechanisms of Ageing and Development 107 197-203.

Lin D, Sugawara T, Strauss JF III, Clark BJ, Stocco DM, Saenger P, Rogol A \& Miller WL 1995 Role of steroidogenic acute regulatory protein in adrenal and gonadal steroidogenesis. Science 267 1828-1831.

Luo L, Chen H \& Zirkin BR 2001 Leydig cell aging: steroidogenic acute regulatory protein (StAR) and cholesterol side-chain cleavage enzyme. Journal of Andrology 22 149-156.

Matsumoto AM 2002 Andropause: clinical implications of the decline in serum testosterone levels with aging in men. Journals of Gerontology Series A: Biological Sciences and Medical Sciences 57 M76-M99.

Miller WL 1988 Molecular biology of steroid hormone synthesis. Endocrine Reviews 9 295-318.

Papadopoulos V, Liu J \& Culty M 2007 Is there a mitochondrial signaling complex facilitating cholesterol import? Molecular Cell Endocrinology 265-266 59-64.

Payne AH \& Hales DB 2004 Overview of steroidogenic enzymes in the pathway from cholesterol to active steroid hormones. Endocrine Reviews 25 947-970.

Payne AH \& Youngblood GL 1995 Regulation of expression of steroidogenic enzymes in Leydig cells. Biology of Reproduction 52 217-225.

Phillips MC, Johnson WJ \& Rothblat GH 1987 Mechanisms and consequences of cellular cholesterol exchange and transfer. Biochimica et Biophysic Acta 906 223-276.

Privalle CT, Crivello JF \& Jefcoate CR 1983 Regulation of intramitochondrial cholesterol transfer to side-chain cleavage cytochrome P-450 in rat adrenal gland. PNAS 80 702-706.

Rao RM, Jo Y, Leers-Sucheta S, Bose HS, Miller WL, Azhar S \& Stocco DM 2003 Differential regulation of steroid hormone biosynthesis in R2C and MA-10 Leydig tumor cells: role of SR-B1-mediated selective cholesteryl ester transport. Biology of Reproduction 68 114-121.

Rapta P, Misik V, Stasko A \& Vrabel I 1995 Redox intermediates of flavonoids and caffeic acid esters from propolis: an EPR spectroscopy and cyclic voltammetry study. Free Radical Biology and Medicine 18 901-908.

Resko JA, Norman RL, Niswender GD \& Spies HG 1974 The relationship between progestins and gonadotropins during the late luteal phase of the menstrual cycle in rhesus monkeys. Endocrinology 94 128-135.

Schumacher M, Schwarz M \& Leidenberger F 1985 Desensitization of mouse Leydig cells in vivo: evidence for the depletion of cellular cholesterol. Biology of Reproduction 33 335-345.

Stocco DM 2001 Star protein and the regulation of steroid hormone biosynthesis. Annual Review of Physiology 63 193-213.

Townson DH, Wang XJ, Keyes PL, Kostyo JL \& Stocco DM 1996 Expression of the steroidogenic acute regulatory protein in the corpus luteum of the rabbit: dependence upon the luteotropic hormone, estradiol-17 beta. Biology of Reproduction 55 868-874.

Vermeulen A 2000 Andropause. Maturitas 34 5-15.

Wang XJ, Liu Z, Eimerl S, Timberg R, Weiss AM, Orly J \& Stocco DM 1998 Effect of truncated forms of the steroidogenic acute regulatory protein on intramitochondrial cholesterol transfer. Endocrinology 139 3903-3912. 
Wang XJ, Walsh LP, Reinhart AJ \& Stocco DM 2000 The role of arachidonic acid in steroidogenesis and steroidogenic acute regulatory (StAR) gene and protein expression. Journal of Biological Chemistry $27520204-20209$.

Wang XJ, Dyson MT, Mondillo C, Patrignani Z, Pignataro O \& Stocco DM 2002 Interaction between arachidonic acid and cAMP signaling pathways enhances steroidogenesis and StAR gene expression in MA-10 Leydig tumor cells. Molecular and Cellular Endocrinology 188 55-63.

Wang XJ, Dyson MT, Jo Y \& Stocco DM 2003a Inhibition of cyclooxygenase-2 activity enhances steroidogenesis and steroidogenic acute regulatory gene expression in MA-10 mouse Leydig cells. Endocrinology 144 $3368-3375$.

Wang XJ, Dyson MT, Jo Y, Eubank DW \& Stocco DM $2003 b$ Involvement of 5-lipoxygenase metabolites of arachidonic acid in cyclic AMP-stimulated steroidogenesis and steroidogenic acute regulatory protein gene expression. Journal of Steroid Biochemistry and Molecular Biology 85 159-166.

Wang XJ, Shen CL, Dyson MT, Eimerl S, Orly J, Hutson JC \& Stocco DM 2005 Cyclooxygenase- 2 regulation of the age-related decline in testosterone biosynthesis. Endocrinology 146 4202-4208.
Williams CA, Harborne JB, Newman M, Greenham J \& Eagles J 1997 Chrysin and other leaf exudate flavonoids in the genus Pelargonium. Phytochemistry 46 1349-1353.

Zazopoulos E, Lalli E, Stocco DM \& Sassone-Corsi P 1997 DNA binding and transcriptional repression by DAX-1 blocks steroidogenesis. Nature $390311-315$

Zhao D, Duan H, Kim YC \& Jefcoate CR 2005 Rodent StAR mRNA is substantially regulated by control of mRNA stability through sites in the $3^{\prime}$-untranslated region and through coupling to ongoing transcription. Journal of Steroid Biochemistry and Molecular Biology 96 155-173.

Received in final form 4 February 2008

Accepted 13 February 2008

Made available online as an Accepted Preprint 13 February 2008 